\title{
En búsqueda de una tercera vía
}

\author{
Francisco Javier Ibisate*
}

\section{Resumen}

"La globalización debe adquirir un compromiso social, que no tenga como contrapartida la miseria y la exclusión de millones de seres humanos en el planeta". Estamos inmersos en una escalonada crisis económico-financiera y no podemos hablar de crisis coyuntural, sino de crisis estructural por sus efectos económicos y sociales. Las terceras vías no buscan sólo una reestructuración del funcionamiento económico, sino reconversiones sociales y humanas más profundas. El exponente de terceras vías no defiende sus propios intereses, sino la superviviencia digna de millones de seres humanos. Ota Sik ha sido uno de los hombres que ha buscado una economía "con rostro humano". No la encontró ni en el capitalismo liberal ni en el socialismo-comunista de su tiempo. Ésta ha sido también la historia del siglo XX: la búsqueda de terceras vías.

\section{1. ¿Cómo vemos el mundo actual?}

El final de un siglo-milenio es un tiempo propicio para hacer una pregunta: ¿cómo vemos el mundo actual? La respuesta es clara: lo vemos muy mal. Estamos inmersos en una escalonada crisis económico financiera que, luego de golpear frontalmente a muchas naciones, sigue generando expectativas y oscuras interrogantes en el restó de las economías. No se puede hablar de crisis co- yuntural, de simple ajuste técnico, sino de crisis estructural por sus efectos económicos y sociales. Varios autores la han comparado con la crisis mundial de 1930. En los años de crisis profundas es cuando han surgido las terceras vías, unas en forma pacífica, otras más violentas.

A lo largo del siglo $\mathrm{XX}$ hemos sido testigos de varias terceras vías: la revolución keynesiana y los regímenes que en ella se inspiraron, luego de la

* Decano del Departamento de Ciencias Económicas y Sociales de la Universidad Centroamericana "José Simeón Cañas". 
segunda guerra mundial, pueden catalogarse como una tercera vía. La serie de "perestroikas", década tras década intentadas y siempre sofocadas, en el Este europeo hubieran sido otros ejemplos de terceras vías. Más difícil de calificar como terceras vías fueron los regímenes fascista y nacional-socialista, que algunos autores catalogan como regímenes corporativistas. Bajo cualquier catalogación, hablar de tercera vía es aceptar la preexistencia de una primera y de una segunda vía. De esta realidad confrontativa e irreconciliable de las dos primeras vías nace el problema de la supervivencia de toda tercera vía, porque ella es la negación, no de uno, sino de dos contrarios. Y los contrarios van a rechazar también a las terceras vías.

Sabemos que la "teoría de la coexistencia pacífica", formulada en los años 1920 , nunca ha sido - hasta M. Gorbachov- una teoría de la "pacífica coexistencia" de parte de ninguno de los sistemas opuestos. Su principio inspirador es el adagio romano: "si vis pacem para bellum" [si quieres la paz, prepara la guerra]. De ahí nace la desgastante carrera armamentística que, por su capacidad de inminente destrucción; ha sido un factor disuasivo del exterminio global. Sin embargo, el hecho de que no se haya dado una conflagración atómica mundial no ha sido obstáculo para que los regímenes y sus ideologías político-económicas hayan perseguido y eliminado sistemáticamente a sus opositores e incluso a los exponentes de las terceras vías. En palabras más breves y más drásticas, la historia de las vías opuestas e irreconciliables está jalonada de "crímenes contra la humanidad". Este aspecto ha sido desarrollado en forma más extensa y documentada en un reciente comentario al Mensaje de Juan Pablo II, sobre el tema de la paz y los derechos humanos, de enero $1999^{\prime}$.

Traslado uno de los párrafos de dicho mensaje que dio origen al citado artículo y que también justifica la búsqueda actual de una tercera vía. "La historia contemporánea ha puesto de relieve de manera trágica el peligro que comporta el olvido de la verdad sobre la persona humana. Están a la vista los frutos de ideologías como el marxismo, el nazismo y el fascismo, así como también los mitos de la superioridad racial, del nacionalismo y del particularismo étnico. No menos perniciosos, aunque no siempre tan vistosos, son los efectos del consumismo materialista, en el cual la exaltación del individuo y la satisfacción egocéntrica de las aspiraciones personales se convierten en el objetivo último de la vida. En esta perspectiva, las repercusiones negativas sobre los demás son consideradas del todo irrelevantes"2. Esperamos que el neolibelismo se dé por aludido, porque le dedican más líneas y una seria condena: "las repercusiones negativas sobre los demás son del todo irrelevantes". Difícil decir más en dos líneas.

La historia de crímenes contra la humanidad no es un serial que termina con el juicio de Nüremberg, 1945; el Mensaje del Papa avala "la reciente iniciativa de una Conferencia Diplomática de las Naciones Unidas que, con una deliberación específica, ha aprobado los Estatutos de una Corte Penal Internacional, destinada a determinar las culpas y castigar a los responsables de los crímenes de genocidio, crímenes contra la humanidad, crímenes de guerra y de agresión" (p. 12). A estos crímenes, teñidos de sangre, se agregan los crímenes blancos, que legitiman una tercera vía: "Optar por la vida comporta el rechazo de toda forma de violencia: la violencia de la pobreza y del hambre que aflije a tantos seres humanos" (p. 8). Veremos enseguida cómo el foro de Davos (Suiza) se expresa sobre estos exterminios masivos, que toman forma de pobreza, miseria y exclusión.

Las terceras vías no buscan sólo una reestructuración del funcionamiento económico, sino reconversiones sociales y humanas más profundas. Dentro de cierta simplificación, se pudiera decir que nuestro siglo se ha caracterizado por un enfrentamiento de derechas e izquierdas. Sin embargo, en su funcionamiento histórico nos encontramos con dos regímenes de "derechas", de muy relativas minorías que, en búsqueda de sus privilegios personales, imponen todo su saber y poder sobre las mayorías nacionales y continentales. En consecuencia no admiten ninguna oposición, ni siquiera la formulación de terceras vías. Ésta es la tesis de Ota Sik al escribir, en 1972, "La tercera vía" , luego que las tropas del Pacto de Varsovia

1. F.J. Ibisate, "Jornada mundial de la paz, 1999. El siglo XX y los derechos humanos", Realidad, 67, enero, 1999.

2. Juan Pablo II, "Jornada mundial de la paz. El secreto de la duradera reside en el respeto de los derechos humanos", 1 de enero de 1999.

3. Ota Sik, La tercera vía ..., México: F.C.E., 1977. 
troncharan la Primavera de Praga, en 1968, de لla cual él fue el principal inspirador.

\section{El recuerdo de Ota Sik}

Tal vez hoy día no se ponga en peligro la vida de los exponentes de terceras vías y las podemos discutir en forma pacífica. La oposición frontal a las terceras vías ha adquirido nuevas modalidades, físicamente menos agresivas, pero de mayores consecuencias humanas. El exponente de terceras vías no defiende sus propios intereses, sino la supervivencia digna de millones de seres humanos. Ota Sik es un ejemplo histórico de tantos hombres de búsqueda de un modelo social, de rostro humano; él conoció las atrocidades de los llamados modelos opuestos. El prólogo a su obra de 1972 mantiene una fresca actualidad y sirve para explicar las trabas impuestas a las terceras vías. El hilo conductor de su tesis es una frase: "Ni con unos ni con otros me puedo identificar en teoría". De ahí nace su búsqueda de un futuro objetivo: "For a humane economic democracy", 19854. Traslado algunas reflexiones de su prólogo, en 1972, dejando de lado las incriminaciones más directas al régimen que puso fin a su Primavera de Praga.

"A ambos lados operan fuerzas conservadoras, cuya vinculación personal con uno u otro sistema les hace imposible reconocer los propios conflictos internos e impedimentos para el desarrollo. Trátese de privilegios económicos o de atractivas posiciones de poder, sea el mundo occcidental de hoy o el socialista del Este europeo, es un conservadurismo de muy desmedrado fundamento el que canta al unísono el mismo estribillo: todas las reformas que se hagan a nuestro sistema son un peligro para nuestra sociedad y para sus miembros" (p. 7).

"No comparto la opinión de que se pueda de alguna manera idear una forma de sociedad sin que ocurran algunos conflictos sociales. Esto no quiere decir, sin embargo, que sea preciso atenerse con exclusividad a los sistemas que hoy prevalecen. Los dogmáticos, tanto del capitalismo como del comunismo, se hallan en el mismo plano

metodológico al quedarse en la disyuntiva de «o esto o aquello»; el abandono del sistema opuesto quiere decir para ellos que se acepta incondicionalmente el propio. Para mí, en cambio, no se sigue del reconocimiento y crítica de las contradicciones evolutivas de una sociedad que se deban preterir o denegar los conflictos que hay en la otra. Se trata más bien de la superación de las fallas esenciales de un sistema y otro"... (p. 10).

"Los ideólogos conservadores de ambos flancos se encuentran a gusto en esta situación y persiguen sin más al teórico que trate de salvar la brecha entre las dos ciencias. Cual ocurre con los políticos conservadores de un sistema y otro, va en ello la conservación de su propio reino; un reino intelectual para unos y para otros un reino político muy material. A pesar de la vida cotidiana, los representantes de ambos sistemas contrapuestos sabrán cómo aguantar la existencia de la ideología de los otros, mientras el propio reino quede intocado. Por este lado, los ideólogos conservadores de los dos sistemas se entienden muy bien en un respecto: en conjurar todas las reformas y todas las ideas de convergencia. Tales ideas minan sus posiciones de poder y son mucho más peligrosas que las viejas ideas enemigas, las que al cabo se han reprimido y acallado con toda tranquilidad".

“A ambos lados hay verdades a medias, así como fallas, simplificaciones y dogmas sin ningún valor. Quien aborrezca verse en un mundo dividido, donde sólo se imponen los intereses de las

4. Ota Sik, For a humane economic democracy, Pracger, Nueva York, 1985. 
grandes potencias contra y sobre los intereses de las naciones pequeñas; quien aborrezca vivir en un mundo donde sólo se pueden enseñar las ideas conformes con el poder, que sólo generan en millones de hombres la psicosis de «hostilidad»; quien crea en la posibilidad de humanizar nuestra sociedad y no se deje tranquilizar con las realidades de la amenaza nuclear; quien aborrezca todo eso, deberá buscar vías para la superación de esta fosa teórica entre los dos mundos... Desde siempre la nueva praxis ha salido de nuevas ideas, y en un mundo dividido por ideas de poder antagónico nunca podrá asegurarse una paz duradera y practicable" ( $p$. 13). "A largo plazo resultan más firmes los conocimientos científicos que los más fuertes intereses del poder; pero contra la fuerza bruta siempre en la historia ha sido preciso armarse de paciencia" (p. 10).

¿Por qué traer a cuento este recuerdo de Ota Sik? Porque desde la década de los setenta fue uno de los hombres que estuvo a la búsqueda de una economía "con rostro humano". No la encontró ni en el capitalismo liberal ni en el socialismo-comunista de su tiempo. "Ni con unos ni con otros me puedo identificar en teoría". La Primavera de Praga (1968) era un intento de economía social que, desde el exilio de Suiza, dejó plasmada en su obra: For a humane economic democracy (1985). Los socialismos reales del Este europeo contaron con grandes economistas - algunos de ellos premio Nobél de economía - que década tras década formularon profundas reestructuraciones, con la idea de democratizar el modelo: lastimosamente fueron silenciados, exiliados e incluso algunos corrieron peor suerte. La Perestroika de Gorbachov ("más socialismo más democracia") fue el canto del cisne, el último intento por instaurar una economía democrática humana. El modelo quebró política y económicamente.

Tal vez Ota Sik haya asistido al foro económico de Davos, en Suiza, en cuya convocatoria se lamenta y reclama la ausencia del rostro humano en "La globalidad responsable". En los documentos de antecedentes hay textos muy fuertes: "La globalización debe adquirir un compromiso social, que no tenga como contrapartida la miseria y la exclusión de millones de seres humanos en el planeta". En Davos se ha dicho que "nos hallamos de nuevo en el posneoliberalismo", dando a entender que cerramos el siglo con la búsqueda de otras terceras vías. Ésta ha sido también la historia del siglo $\mathrm{XX}$ : la búsqueda de terceras vías.

\section{Plan y mercado van de la mano}

A lo largo del siglo XX no sólo ha habido modelos irreconciliables e ideológicamente opuestos, también han existido teorías de la convergencia y modelos históricos de convergencia, aunque no todos fueran aceptados espontáneamente. Quienes hayan seguido la historia económica del siglo XX podrán recordar que —durante cincuenta años, de Karl Kaustky a Joseph Schumpeter- se fue elaborando un modelo teórico, Lerner-Lange, que conjugaba la planificación global con el juego del mercado interempresarial y la aplicación del cálculo económico, modelo de posible aplicación para una economía socialista. Fue una larga búsqueda de una tercera vía Plan-Mercado. La llamada Reforma-Liberman, aprobada oficialmente en la ahora ex Unión de Repúblicas Socialistas Soviéticas, en 1965, tenía un cercano parentesco con ese modelo teórico, y sobre todo lo tenía el tronchado ensayo de la Primavera de Praga. Pero desde ese lado se cerró la tercera vía de convergencia.

En Europa occidental de posguerra se desarrollaron con gran fortaleza dos terceras vías, más bien complementarias que divergentes. La "Economía Social de Mercado", en Alemania occidental, es un rechazo al hipercentralismo e irracionalidad del nacional-socialismo y, al mismo tiempo, se distancian del liberalismo de laisez-faire en la tarea de la reconstrucción de una Alemania humana y físicamente destruida por la guerra. "La Economía Social de Mercado" en donde sus iniciadores, Alfred Müller-Armack, Ludwig Erhard y Walter Eucken, integran la política social en la política económica. En su aplicación "alemana", la palabra "social" no es un atributo de adorno con fines de propaganda política, como ha sucedido en nuestro país en las dos últimas décadas. La Economía Social de Mercado fue en Alemania una fehaciente réplica a las tesis ultraliberales de Misses-Hayek, y salen sobrando los comentarios sobre sus éxitos económico-sociales de esta tercera vía.

En el resto de Europa occidental se desarrolló el modelo calificado - dentro de ciertas divergencias- como "Estado Social de Bienestar", que durante tres décadas combinó las mayores tasas de crecimiento con una positiva distribución de ingre- 
sos (crecimiento con equidad) y con el auge de la seguridad social. Como mecanismo de funcionamiento integraba la planificación indicativa (revolución keynesiana), o planificación democrática, con la participación conjunta de representantes de todas las ramas productivas. El soporte económico sería la contabilidad nacional, donde las matrices intersectoriales constituirían el radar de la planificación concertada. La inspiración del modelo económico se fundamentaba en la idea de libertad e igualdad reales y en la solidaridad ciudadana.

Este modelo, auténtica tercera vía, surge como la respuesta histórica a la crisis total de la economía de mercado; la crisis de 1930 es la décimo tercera crisis del liberalismo (gravísima crisis de desempleo, de quiebra económica, comercial y financiera), que deriva en grandes agitaciones sociales. Es una tercera vía entre el laissez-faire y el régimen centralizado por una planificación militarizada de toda la economía. Adicionalmente, los inspiradores del modelo logran que países enfrentados en dos guerras mundiales se integren en un mercado común. Se podrá decir, con toda razón, que la constitución de este mercado común nace como un poder compensador entre el gran mercado común de Estados Unidos y el mercado común del bloque-Este (CAEM o COMECON). Bajo cualquier hipótesis es una marcha en la línea de la convergencia y una lección para nuestros depasados nacionalismos, en un mundo donde hay que respetar las fronteras, precisamente, porque no tienen ninguna importancia.

Es lógico que luego de la descomposición político-económica de los socialismos reales y ante los desequilibrios políticos, económicos y sociales gestados por el actual neoliberalismo, en Europa Occidental renacen las nostalgias y los proyectos de reactualización del Estado Social de Bienestar, a sabiendas de su crisis luego de 1970 . Al fin y al cabo, todos los modelos y sistemas han conocido sus fases de crecimiento, euforia, tensión, recesión y crisis, que explican la proliferación de tantos "Neos". El Estado social de bienestar vuelve a presentarse como una tercera vía ante la crisis de un neoliberalismo individualista, que niega la solidaridad $^{5}$. Conviene recordar que la mayoría de gobiernos de Europa Occidental son gobiernos de centro-izquierda. La historia gira sobre sí misma.

\section{Un paréntesis nacional}

Hace diez años, el gobierno entrante fundamentaba su programa de gestión en un estudio de FUSADES: "Hacia una economía de mercado en El Salvador; bases para una nueva estrategia de desarrollo económico y social" (mayo, 1989). Sus postulados económicos eran los siguientes: (l) La propiedad privada es condición necesaria para la eficiencia de la producción. (2) El mercado libre asegura la mejor asignación de los recursos. (3) La competencia garantiza el funcionamiento del mercado. (4) El Estado tiene un papel subsidiario.

Diez años más tarde, puesta la mano en el pecho, pocas personas aceptarán que con esos postulados hemos logrado un desarrollo económico y social. La Comisión del Plan de Nación publica a inicios de enero 1999- los resultados de 19 mesas de trabajo, donde 211 especialistas nacionales presentan los "Temas claves para el Plan de $\mathrm{Na}$ ción". Baste, de momento, trasladar el enunciado de algunas mesas de trabajo para reconocer que por ese camino nos ha ido mal: Exclusión económica y pobreza; Ciencia y tecnología; Ramas estratégicas de desarrollo y reformas sectoriales pendientes; Desarrollo agropecuario y rural; Nueva cultura laboral y empresarial; Etica en El Salvador; Reforma fiscal y priorización de la inversión pública; Medio ambiente y desarrollo; Reforma del sistema de salud; Estrategia nacional de vivienda; Educación cultura y deportes...

Existen varios aspectos importantes en este breve enunciado. En primer lugar, que junto con algunos logros, hay serias deficiencias y rezagos en todos esos temas claves. En segundo lugar y no menos importante que el mismo contenido, está el deseo de parte de todo este grupo profesional - de diversas ideologías- de participar académicamente en la reconversión del país. Una vez más, la mano invisible del mercado necesita de cirugía profunda. En tercer lugar, que vuelva a aparecer la urgencia de un Plan de Nación. Volvemos a reflexionar sobre un debate surgido en los años de 1920: la integración de los dos reguladores de la economía, el plan y el mercado.

Este debate aflora en una de las mesas que no ha sido citada: "La modernización del Estado". Al hablar de los roles del Estado aparecen posiciones

5. F.J. Ibisate, “Propuestas de bienestar ¿con Estado de bienestar?”, ECA, 1996, pp. 865-887. 
ideológicas diferentes; entre ellas una frase, tomada de una publicación del Ing. Héctor Dada Hirezi, plantea bien la problemática: "Aprovechar la ventaja del mercado, limitando sus características concentradoras, aprovechar las ventajas de la intervención del Estado, sin caer en restriciones intolerables a la libertad social, es un objetivo difícil de lograr pero cuya búsqueda es una obligación" (p. 85).

Esta afirmación de Héctor Dada marca un avance porque, al mismo tiempo, señala la necesidad y la dificultad histórica de integrar los dos reguladores de la economía. Recomienda simultáneamente la modernización del Estado y la humanización del Mercado. Hace diez años no se hubiera tomado en serio esta afírmación que recuerda dos reclamos repetidos; el de los obreros polacos de 1980: "no hay pan sin libertad", y el de las mayorías del tercer mundo: "no hay libertad sin pan”. Estos debates significan un avance.

El redactor de la mesa de trabajo deja entrever esta tensión: "En la discusión sobre el rol del Estado, se expresan posiciones de carácter ideológico o doctrinario en torno a lo que debería ser el papel del Estado y el papel del Mercado en un momento histórico específico. La relación Estado-Mercado es el tema de fondo que a veces se quiere soslayar" (p. 84). Tres páginas antes el redactor comenta: "en lo que se refiere a la esfera económica se puede señalar que se ha impulsado un proceso de reformas económicas, que ha permitido realizar avances sustanciales en la estabilización de la economía. Sin embargo, al haberse dogmatizado el modelo de economía de mercado se abandonaron políticas sectoriales y se cometieron otro tipo de errores que han incrementado los niveles de exclusión social, y han generado limitaciones a un crecimiento económico más sostenible" (p. 81).

El documento inicial de Bases para un plan de nación presentaba la complejidad del tema en nuestras concretas circunstancias: "La naturaleza del Estado como regulador, subsidiario, garante o gestor está en juego en este debate que debe situarse en una dimensión constructiva en función de la necesaria modernización del Estado salvadoreño... Es indudablemente un problema cuya solución será decisiva y fundamental para la viabilidad y el desarrollo del país a mediano y largo plazo. Este tema requiere discusión y elaboración de un planteamiento claro que constituya un producto de acuerdo político aceptable y práctico" (p. 22).
Esta reflexión va a tomar su tiempo por varias razones. Con frecuencia los mayores enemigos de los Estados han sido los propios gobiemos; sus errores se achacan a todo Estado. Por otro lado hay un denominador común en estas mesas de trabajo: la necesidad de un Plan de Nación que, de alguna forma, introduce un nuevo regulador de la economía global. En tercer lugar, la conciencia de que permanecen los problemas (nudo gordiano) de la pobreza, exclusión social y desempleo; los postulados de una economía de mercado suelen agudizarlos. Ideologías diferentes determinan propuestas diferentes.

El Salvador es una parcela de la "aldea" global y nuestras reflexiones se enriquecen (¿y complican?) si las enmarcamos en ese entomo mundial. La economía global se ha convertido en una inmensa sociedad anónima, donde nadie se hace responsable porque todos se sienten sometidos a los incontrolables vaivenes del mercado financiero, teledirigido por la especulación. Veremos enseguida que el debate se centra en cómo controlar a los capitales migrantes de corto plazo; pero queda la pregunta: ¿quién mueve a estos capitales especulativos?

El término "mercado" se amplia y complica; los mismos defensores del libre mercado se ven arrollados por los reflujos de su mercado. Mercado son miles de megaempresas, cuya factura de venta anual supera veinte veces nuestro producto nacional. Mercado es, sobre todo, la red de bolsas de valores que en cuatro días de compras-ventas movilizan un flujo de dinero equivalente al Producto Interno Bruto anual de Estados Unidos. Y dentro de la red financiera se ha generado esa "economía de casino", sin reglas, donde los especuladores juegan al "póquer del mentiroso". Mercado son los grandes monopolios u oligopolios de los medios de comunicación social que nos injertan los nuevos valores de competir, ganar y consumir. Mercado son también los resultados de la economía de mercado en las economías emergentes y en las sumergidas, y sobre todo en las clases marginadas de todas las naciones. Mercado son fuerzas más poderosas y complejas, económicas y extraeconómicas, que transcienden el dilema de plan-mercado. Sobre estos aspectos han girado las reflexiones y los debates en reciente foro intemacional, que nos iluminará en nuestro debate nacional.

\section{El Foro Económico de Davos}

Del 28 de enero al 2 de febrero de 1999 tuvo lugar el 29 Foro Económico de Davos (Suiza), 
donde concurrieron más de mil líderes de empresa, unos 300 dirigentes políticos, incluidos 40 jefes de gobiemo y alrededor de unos 300 expertos en cuestiones económicas. La agenda a deliberar era: "La globalidad responsable: la gestión del impacto de la globalización". Los primeros comentarios ya presagiaban un tenso debate. La globalización debe adquirir un compromiso social, que no tenga como contrapartida la miseria y la exclusión de millones de seres humanos en el planeta. Tema de agenda sería el fracaso de los organismos multilaterales, responsables del orden económico intemacional desde 1945. El famoso financiero y filántropo George Soros, participante en el foro, había dicho que: "El FMI no es parte de la solución; es parte del problema", dando a entender que su gestión no ha sido adecuada. Desde la convocatoria se presagiaba la tensión y también la contrarréplica de quienes estarían sentados en el banquillo de los acusados.

Los organizadores del evento lo introducen con tonos críticos. "Esta crisis es el resultado de una globalización que ha sido conducida de manera irresponsable. Los problemas creados por la mundialización han desembocado en una crisis "sistémica". O se diseñan nuevas medidas para hacer frente a la crisis o estamos condenados a entrar en un período de caos endémico y sistemático" (C. Swadja). El principal animador de esta reunión, Klaus Achwad, "sostiene la necesidad de crear mecanismos globales e institucionales para lograr que la globalización se traduzca en fuente de bienestar para millones de personas, que han sido condenadas a la miseria y al desempleo".

Desde su convocatoria se van agregando otros comentarios críticos. "Mise-
La economía global se ha convertido en una inmensa sociedad anónima, donde nadie se hace responsable porque todos se sienten sometidos a los incontrolables vaivenes del mercado financiero, teledirigido por la especulación. desafíos económicos intemacionales no puede seguir siendo monopolio exclusivo de las grandes potencias, a cuyas reuniones asisten los representantes y líderes políticos de las naciones emergentes como "invitados de piedra". De ahí la necesidad de que el fenómeno recupere su rostro humano, frente a la "economía de casino", que carcome los cimientos del sistema, atempere las desigualdades que produce entre economías desarrolladas y los mercados emergentes".

La convocatoria presagiaba que el Fondo Monetario Internacional podría ser sentado en el banquillo de los acusados. El gran economista Jeffrey Sachs, en su visita a El Salvador, había dicho que el FMI "es una institución frustrante, pues nunca admite cuando ha cometido un error. No importando lo que pase, ellos supuestamente están en lo correcto y todos los demás son los que se equivocan. Este tipo de arrogancia no es permisible para una institución internacional" periodísticos, (Internet) el Fondo Monetario Internacional de Davos sigue siendo el FMI de Jeffrey Sachs; no admite la crítica e impone su crítica. De todas formas, el foro de Davos no ha sido un panegírico del neoliberalismo, sino más bien un martirologio de sus víctimas.

\subsection{Davos: la globalidad responsable}

Manuek Castells, economista de Berkeley (California) y participante en este foro, comenta brevemente: "El mundo según Davos"”. Afirma que hay un consenso en que "el proceso de globalización se está desarrollando de forma irresponsable, en el sentido literal de la palabra. O sea sin que nadie tenga control o ria y desempleo, destruccción masiva de la riqueza financiera y material. Estados sometidos a la especulación, un capitalismo salvaje que erosiona las normas más elementales de la convivencia, son algunos de los rasgos que advertirían una globalización irresponsable". "La gestión de los de descontrol ya había sido admitido, aunque involuntariamente, en la reunión del Fondo Monetario Internacional, Banco Mundial y ministros de finanzas del G-7, en la reunión de Washington, en octubre de 1998. Allí uno de los ministros de finan- responsabilidad sobre el mismo". Este consenso

6. El Diario de Hoy, 23 noviembre de 1998, p. 51.

7. M. Castells, "El mundo según Davos", El País, 12 de febrero de 1999. 
zas dio como gran respuesta: "No pueden esperar que saquemos un conejo del sombrero, que solucione la situación". El comentarista Michael Elliot concluía: "A la pregunta: ¿quién está a cargo de la economía global? podemos ahora responder: Nadie. Un mundo sin controles - sin reglas- es un mundo sin seguridad" ( $E C A, 1998$, pp. 901 y 905).

El consenso avanza un poco más y luego se detiene, divide y enfrenta. "Se considera asimismo que sus efectos son cada vez más perturbadores en casi todo el mundo, cuando, después de la crisis mexicana y del hundimiento del milagro asiático, se ha producido la bancarrota de Rusia y la devaluación del real brasileño, que amenaza la estabilidad económica latinoamericana. Se constata que la globalización es imparable. Es un proceso objetivo, y fuera de ese proceso sólo hay marginación económica, al menos en el marco de la economía de mercado, que al final se ha impuesto como forma universal. Pero el consenso se detiene ahí. En cuanto se trata de encontrar fórmulas para hacer frente a los problemas suscitados por la globalización, los intereses se dividen, las situaciones propias sesgan la receta, las ideologías chocan y la intensidad de la aplicación en la búsqueda de nuevas políticas depende de la intensidad con que se viven los problemas".

Este comentario de M. Castells sintetiza el consenso general sobre la forma inadecuada en que se ha desarrollado la globalización, sus crecientes perturbaciones en casi todo el mundo y sintetiza la irresponsabilidad mayor: los gestores de esta evolución regresiva no admiten su responsabilidad y se niegan a cambiar de políticas. "La opinión dominante es que, en lo esencial, aunque sería deseable controlar la globalización, no se puede hacer sin quebrar el mercado, sin resucitar la excesiva intervención gubernamental y sin espantar a los innovadores que crean tecnología y a los inversores que ponen el dinero. La idea, en principio mayoritaria, de avanzar hacia una nueva arquitectura de regulación internacional, choca, cuando se intenta concretar, con la oposición de los Estados Unidos y el
Fondo Monetario Internacional, el rechazo de las grandes empresas financieras y de los mercados bursátiles, y el desacuerdo profundo entre Gobiernos y entre técnicos sobre en qué podría consistir esa regulación".

Era de esperar la confrontación y las resistencias de las fuerzas ejes del modelo. Pero la misma confrontación encierra positivos avances. Los turiferarios del "mercado" podrán comprender que este término significa una estructura más compleja y más destructiva de lo que ellos tienen en mente al utilizar este concepto. Podrán entender que este mercado no tiene nada de autorregulado ni de regulador de la producción. En la conferencia de Davos se ha vuelto a repetir que este modo de mercado globalizado es el responsable de la marginación social, de la miseria y desempleo de millones de seres humanos. Esto mismo lo acababa de decir Juan Pablo II en sus mensajes del 1 y 22 de enero de 1999.

De acuerdo con M. Castells, se llegaron a expresar dos conclusiones sorpresivas: "Así, en último término, parece que hay que instalarse en la volatilidad financiera y en la inestabilidad económica y aprender a vivir en un mundo incierto, pero creativo y con potencial de ganancia". Es decir, que el potencial de ganancia justifica el resto de extorsiones mundiales. El capitalismo se autodefine, pero no se corrige. Incluso se estaría "humanizando" la profecía del rebalse: "De modo que el lado oscuro de la globalización se sitúa, sobre todo, en el drama humano que para cientos de millones de seres humanos representa $-\mathrm{y}$ esa responsabilidad se transfiere a las instituciones internacionales humanitarias, a las religiones y a la filantropía- un tema recurrente entre algunas de las más destacadas figuras empresariales". Ésta es la solidaridad de los líderes del mercado. Como dijo Juan Pablo II en su mensaje del 1 de enero: "En esta perspectiva, las repercusiones negativas sobre los demás son consideradas del todo irrelevantes". 
Junto con la inseguridad, la volatilidad y la filantropía se anuncia un rebalse en estado de hibernación: "Por otro lado se espera que la promesa tecnológica, con tecnologías cada vez más potentes y más baratas, que se difundirán entre toda la población, contribuya decisivamente a resolver los problemas. De modo que, aun aceptando que estamos en una tormenta de transición a un nuevo orden económico internacional, caracterizado por el desorden como forma de vida, se confía en que el dinamismo del sistema tecno-económico que hemos creado, supere por sí mismo las actuales contradicciones". No dejan de ser irónicas estas promesas cuando los creadores de cualquier tecnología defienden a capa y espada sus derechos de propiedad intelectual y son reacios al derrame de sus tecnologías. Lo contradictorio de un modelo regulador es que deba delegar la última solución a la solidaridad de "instituciones humanitarias internacionales, a las religiones y a la filantropía". La conferencia de Davos ha sido bien aleccionadora.

También ha habido espacios para el vuelo de los buenos espíritus. Jorge G. Castañeda, profesor de la UNAM de México, viene a decir que el foro de Davos marca la transición de una a otra era. Por ahí inicia su artículo: "Davos y el neoliberalismo" . Comienza afirmando que "la sorpresa de este año en el Foro Económico Mundial estribó justamente en la desaparición del optimismo beato, de la ciega exaltación del modelo, de la pureza impoluta e imprescindible del mercado. Al contrario, comprobamos algo ya presentido por muchos: nos hallamos de nuevo en el pos-neoliberalismo, transición que se detecta en tres tendencias, una de ellas clara y contundente y dos sujetas a mayores reservas y matices".

Hace dos años, Alain Tourraine, Director del instituto de Estudios Superiores de París, preconizaba la era de posneoliberalismo. "Nadie puede desear que se ensanche el abismo que separa el mundo económico de los mundos político y cultural. Por tanto es necesario hacer lo posible para que se forme una voluntad colectiva que ponga fin al desarrollo sin freno del capitalismo, es decir, de la economía de mercado, mientras rechace todo control político y social de sus actividades. Hay que restablecer el control de los medios económi-

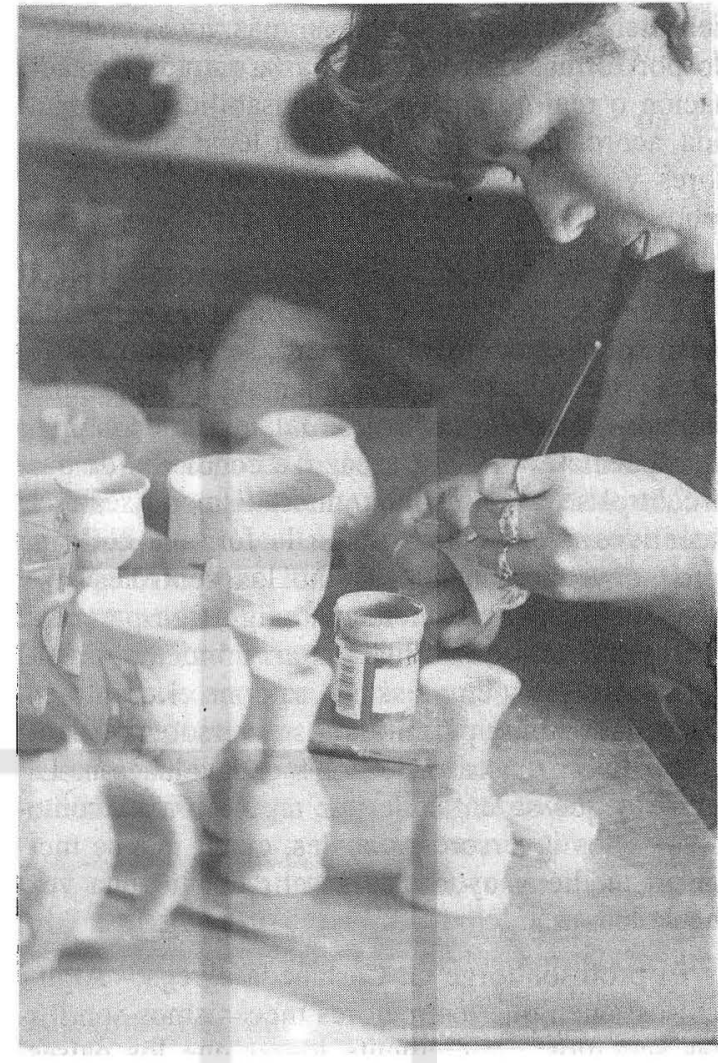

cos para las finalidades políticas y sociales. La tormenta se escucha casi por todas partes, excepto en los Estados Unidos, y en todos los países, incluido Estados Unidos, aumenta el temor de una crisis económica grave que incrementará la pobreza, la desigualdad y la exclusión de una manera insoportable. El largo silencio de la época neoliberal debe terminar y el debate público sobre los fines y los medios de la economía debe revivir. No perdamos más tiempo"'. En el foro internacional de Davos se vuelve a romper este silencio.

La primera tendencia, clara y contundente, es "un consenso sobre la necesidad de controlar los flujos mundiales de capital de corto plazo. Las razones son obvias: destruyen economías a diestro y siniestro, sin mayores contemplaciones por equilibrios "sólidos" o precarios, por monedas subvaluadas o sobrevaluadas, por déficit razonables 0 abultados, por sistemas bancarios sanos o en plena

8. J.G. Castañeda, "Davos y el neoliberalismo", El País, 10 de febrero de 1999.

9. A. Tourraine, "El final de una ilusión", El País, 10 de diciembre de 1997. 
debacle. Cada vez se escuchan más voces clamando por formas de regulación a la entrada de cada nación o región, por una responsabilidad compartida, acordada exante y con valor legal entre acreedores y deudores cuando las cosas salen mal, y sobre convenios internacionales destinados a supervisar y canalizar los flujos".

También M. Castells había recogido este consenso sobre el control financiero, señalando sus límites y dificultades. "Se aceptan algunas fórmulas limitadas, como el control de la entrada de capitales especulativos a corto plazo, a condición de que el control se haga mediante mecanismos fiscales e incentivos de mercado, según la fórmula chilena, pero no yendo tan lejos como los controles malayos y chinos. Se coincide en exigir transparencia informativa sobre la situación económica y financiera de países y empresas. Y se pone el acento en la legislación que permita a los inversores recuperar su dinero en caso de crisis o devaluación. Es decir, lo que se entiende por regulación es cómo salvar a los inversores globales, evitar que se metan en un lío y ayudarles a salir del lío una vez que se han metido".

El profesor Jorge G. Castañeda agrega: "Algunos sostienen que los mejores mecanismos son los más sencillos: simplemente lograr que los países en desarrollo cesen de elevar sus tasas de interés para atraer capitales; otros sugieren un dispositivo más complejo, incluyendo encajes legales de larga duración, castigos a la salida y otras formas de inhibición a la entrada... Cuando el nuevo canciller alemán, Gerhard Schröder, invoca a Soros en Davos y exige una nueva y enérgica regulación de los flujos financieros especulativos, parece el mundo al revés".

Este "consenso de Davos" prolonga el debate surgido en la reunión del FMI, BM y el G-7 en Washington, en octubre de 1998. En dicha reunión estos representantes proponían una solución de medias tintas: "Debemos continuar nuestros esfuerzos por reforzar un sistema internacional de comercio abierto, con libre flujo comercial y mercados de capitales abiertos". Agregan que dicha apertura debe ocurrir en forma "ordenada". Solución ambigüa que equivale a pasear un tigre amarrado con una pita de plástico. Recordábamos que para ese entonces ya emergían opiniones contesta- tarias: "El profesor de Harvard Dani Rodrik, exponiendo lo que parece ser el pensamiento ahora predominante del Banco Mundial, señaló que hay pocas evidencias sobre los beneficios de la libre movilidad de capitales y demasiados signos de los costos que la política de apertura conlleva".

El vicepresidente del Banco Mundial, Joseph Stigliz, que también habló en Davos, dijo el pasado año que "puede ser una idea peligrosa el que los países abran sus economías a un libre juego de capitales, aunque esto es lo que están pidiendo los principales países industrializados. Según Stigliz, los estudios no han demostrado una correlación entre la liberación de capitales y el crecimiento económico. Dicha liberalización suele ir asociada con crisis financieras y aumentos en la desigualdad de los ingresos". En la misma reunión de Washington, economistas poco sospechosos como Samuelson y Krugman planteaban límites a la acción de los mercados: "la política económica se ha vuelto prisionera de los inversores frívolos. ¿Puede cambiar? Sí, pero la solución está estigmatizada, démodé y nadie osa sugerirla; esta política es el control de cambios" (ECA, 1998, pp. 904907).

Siendo éste un punto de consenso en Davos, baste agregar, en forma resumida, el testimonio de quien se ha movido durante cuarenta años en las entrañas de este mercado, George Soros: "Los mercados financieros son inestables por naturaleza, y más todavía los mercados financieros internacionales... Los riesgos de cualquier colapso aumentan porque nuestra comprensión teórica de cómo funcionan los mercados financieros es básicamente defectuosa. La teoría económica se apoya en el engañoso concepto de equilibrio. Desde mi punto de vista, el equilibrio es engañoso, porque quienes participan en el mercado tratan de descontar un futuro que está dictado por las expectivas del mercado... Los participantes en el mercado, si son racionales, reconocerán que más que descontando un futuro equilibrio, están disparando contra un blanco en movimiento"10.

En Davos se ha vuelto a confirmar que en el epicentro del mercado mundial se han gestado unas fuerzas desestabilizadoras, impulsadas por la especulación y facilitadas por la tecnología telemática (más compleja matemática), capaces de

10. G. Soros, "Hacia una sociedad abierta global”, El País, 23 de diciembre de 1997. 
desestabilizar la suerte de las naciones y de grandes empresas gerenciadas con tecnología de punta. La tecnología de la especulación como perturbadora de la tecnología de la producción. Esto es lo que daba a entender Alan Greenspan, director de la Reserva Federal de Estados Unidos: "Dadas las extraordinarias facilidades de comunicación disponibles virtualmente alrededor de todo el mundo, el comercio puede ser iniciado desde cualquier locación; cualquier regulación directa de Estados Unidos, restringiendo su flexibilidad, sin duda alguna induciría a que los fondos más agresivos emigrasen de nuestra jurisdicción" ( $E C A, 1998$, p. 905). Conclusión ambigüa: una jurisdicción sin jurisdicción.

Este epicentro mundial nos lleva a dos sencillas recomendaciones pedagógicas. En los cursos de macroeconomía tendremos que modernizar o actualizar aquel gráfico de cuatro cuadrantes, conocido como la cruz de Hicks-Hansen, que derivaba la formación de las variables L-M a partir de la demanda de dinero, motivo especulación, hoy en forma algo diferente a la desarrollada por Keynes. Desde la introducción de la economía conviene recalcar a los alumnos, junto con las tradicionales curvas de oferta y demanda, la posición invertida de dichas curvas en las bolsas de valores, donde la demanda tiene una pendiente positiva y la oferta una pendiente negativa; ello explica los desequilibrios y las fluctuacio-

En Davos se ha vuelto a confirmar que en el epicentro del mercado mundial se han gestado unas fuerzas desestabilizadoras, impulsadas por la especulación y facilitadas por la tecnología telemática (más compleja matemática), capaces de desestabilizar la suerte de las naciones y de grandes empresas gerenciadas con tecnología de punta. nes de la especulación financiera de corto plazo.

\subsection{Democracia, gobernabilidad y desigualdad}

En Davos no hubo pleno consenso sobre la integración de estas tres variables político-económicas, pero se afirmaron serios avances que supeditan los objetivos del mercado a la primacía de la democracia y de la gobernabilidad. "Hoy no sólo se comprende que en ocasiones la democracia y las «políticas correctas» son contradictorias, sino que a la larga es más importante la primera, porque es condición de las segundas, y no al revés. Más aún, las certezas económicas resultan cues- tionables, y las variaciones en la orientación macroeconómica más amplias de lo esperado".

Jorge G. Castañeda, como profesor de la UNAM, México, aplica estas reflexiones de Davos a la sociedad latinoamericana. "Por último se plantea el tema de la gobernabilidad, propiamente dicha, y la vinculación entre el buen desempeño económico y la vigencia de una sociedad cohesionada, pacífica, ordenada y funcional". En Davos y antes de Davos se reflexiona sobre esta contradicción nacida del mercado: "Cunde la noción de que la creciente desigualdad en las sociedades modernas, no siempre comprensibles y asequibles, carcome y socava las formas de gobernabilidad también modernas. Los ejemplos más notorios son, por supuesto, los latinoamericanos: la región más desigual —no más pobre; la diferencia es importante - del mundo, y que desde hace más tiempo comprueba todos los días cómo la abismal desigualdad en su seno sabotea y destruye Estados de derecho, sistemas electorales, estructuras familiares, zonas urbanas, un medio ambiente sostenible, etcetera. Nadie sabe exactamente de qué modo opera la desigualdad como disolvente social; no se conoce con precisión el nivel donde se ubican los umbrales de ruptura, ni el tipo de desigualdad más peligrosa: de ingresos, de activos o de riqueza, de oportunidades o, como afirma insistentemente Amartya Sen, el premio Nobél de economía 1998, de libertades".
La II Cumbre de las Américas, Santiago de Chile, en abril de 1998, reconoce el problema. "La globalización ofrece grandes oportunidades para el progreso de nuestros países y abre nuevos campos de cooperación para la comunidad hemisférica. Sin embargo, puede también incidir en un aumento de las diferencias entre los países y al interior de nuestras sociedades... La superación de la pobreza sigue siendo el reto más grande al que se enfrenta nuestro hemisferio. Estamos conscientes de que el crecimiento positivo observado en las Américas en los últimos años no ha solucionado todavía los problemas de inequidad y exclu- 
sión""l . Uno de los análisis más objetivos lo hallamos en la publicación: "El neoliberalismo en América Latina" (Realidad, 54, 1996). Desde 1992, la CEPAL planteaba el modelo de crecimiento equitativo: "Equidad y transformación productiva: un enfoque integrado", en oposición a la tesis, entonces en boga, de la doble etapa: primero el crecimiento y luego el rebalse, que nunca ha funcionado.

La contradicción entre desigualdad y gobernabilidad se ha hecho sentir también en el interior de las economías desarrolladas y uno de los autores que más lo ha resaltado es el ya citado Alain Tourraine. "Cuanto más compleja y cambiante es una economía, más difícil es lograr un crecimiento duradero, y la importancia de esta idea proviene de que muestra hasta qué punto los equilibrios intemos de una sociedad se han convertido en condiciones necesarias para el crecimiento de la economía. Estos equilibrios sociales no se mantienen espontáneamente; al contrario, la economía de mercado crea desequilibrios y fuerzas de acumulación y exclusión que amenazan a los equilibrios básicos de la sociedad. Éstos, para ser restablecidos, requieren de la intervención del Estado y de otros agentes propiamente políticos y sociales"12. La respuesta histórica en Europa occidental ha sido que la mayoría de sus gobiernos son de centro-izquierda.

Como cita final se agrega el testimonio de George Soros. "Esto me lleva al problema más confuso: el de los valores y la cohesión social. Toda sociedad necesita tener valores compartidos. Los valores del mercado no sirven para este propósito porque sólo reflejan lo que un participante en el mercado está dispuesto a pagar a otro dentro de un libre intercambio. Los mercados reducen todo, incluidos los seres humanos (mano de obra) y la naturaleza (tierra) a mercancía. Podemos tener una eco- nomía de mercado, pero no podemos tener una sociedad de mercado. Además de los mercados, la sociedad necesita tener instituciones que sirvan para fines sociales, como la libertad política y la justicia social. Estas instituciones existen en países concretos, pero no en la sociedad global. El desarrollo de una sociedad global se ha quedado retrasado respecto al de una economía global. A menos que se acabe con esta distancia, el sistema capitalista global no sobrevivirá"13.

Jorge G. Castañeda, luego de afirmar que nos hallamos de nuevo en el pos-neoliberalismo, concluye así su comentario: "Como se ve, la historia no ha muerto; el mundo no se detuvo con el último gran trastocamiento político ideológico, a saber la desaparición del socialismo". Ahora es el modelo neoliberal de mercado quien ha gestado la gran crisis económico-financiera global. Como afirma Alain Tourraine: "El largo silencio de la época neoliberal debe terminar, y el debate público sobre los fines y los medios de la economía debe revivir. No perdamos más tiempo".

\section{De Davos al Plan de Nación}

En la década de los noventa, sobre todo desde el estallido de la crisis sudasiática (1997) hasta el foro de Davos, se generaliza la conciencia de que el mercado neoliberal ha generado una crisis de dimensiones mundiales, cuyas repercusiones ulteriores nos son aún desconocidas. Estos son datos objetivos, cuya responsabilidad se atribuye al modo y a la dimensión del proceso de globalización. Al mismo tiempo, es una realidad objetiva que la globalización sigue actuando como "Un huracán" (F. Hinkelammmert); que la revolución tecnológica en la informática, microelectrónica, nuevos procesos de producción..., domina al sector real de la produción, generando lo que J. Schumpeter descri-

11. El Diario de Hoy, 22 de abril de 1998, pp. 64-65.

12. A. Torraine, ítem, 10 de diciembre de 1997.

13. G. Soros, item, 23 de diciembre de 1997. 
biera como una "destrucción creativa". Es una realidad que la red de bolsas de valores mundiales, donde se integran las grandes instituciones bancario-financieras, moviliza los mayores flujos de dinero y los capitales especulativos de corto plazo. Es cierto, también, que algunos Estados-Naciones han salido favorecidos en el proceso de la globalización.

Todo ello genera una tensión manifestada en Davos, que ha sido recogida por M. Castells: "La opinión dominante es que, en lo esencial, aunque sería deseable controlar la globalización, no se puede hacer sin quebrar el mercado, sin resucitar la excesiva intervención gubernamental y sin espantar a los innovadores que crean tecnología y a los inversores que ponen el dinero. La idea, en principio mayoritaria, de avanzar hacia una nueva arquitectura de regulación internacional, choca, cuando se intenta concretar, con la oposición de los Estados Unidos y el Fondo Monetario Internacional, el rechazo de las grandes empresas financieras y de los mercados bursátiles y el desacuerdo profundo entre Gobiernos y entre técnicos sobre en qué podría consistir esa regulación".

\subsection{Una crisis cualitativamente distinta}

Aunque para bastantes autores la actual crisis económica y financiera haya tenido repercusiones globales, similares a la de 1930 , hay una diferencia cualitativa entre ambas crisis. En los años de 1930 surge la crisis desde el interior de las economías centrales; nace en la bolsa de valores de Estados Unidos, en pleno auge económico de su gran empresa, se contagia - por efecto dominó- a todas las naciones industriales de Europa, incluida la plaza de Londres, y el boomerang regresa a Estados Unidos. Es decir, que son las economías centrales del hemisferio Norte quienes siente y resienten una crisis común; devalúan en forma competitiva sus monedas, entran en un proceso de mutua desaceleración comercial y terminan rompiendo con el sistema monetario del patrónoro. En el interior de sus economías se gesta el hundimiento de su producto nacional, junto con un desempleo alarmante. Los efectos secundarios, derivados del estancamiento comercial, llegan por carambola a las colonias y países del tercer mundo.
Siendo una crisis que nace y crece en ese horizonte, moviliza a los líderes de esos países centrales a la reunión de Bretton-Woods, en 1945, para construir una nueva arquitectura económica y financiera, bajo la hegemonía de Estados Unidos. De esa fecha datan el Banco Mundial de Reconstrucción y Desarrollo, y el hoy maltraído Fondo Monetario Internacional. En esas circunstancias se adscriben a la "revolución keynesiana", con mayores poderes para el Estado.

La actual crisis de fin de siglo nace en los países emergentes del bloque sudasiático (a exceción de Japón, segunda potencia mundial) y se contagia entre países emergentes o en vías de desarrollo; en su transmisión desempeñan una función activa capitales de corto plazo de los países centrales junto con las medidas impuestas por el Fondo Monetario Internacional. En 1997... los países industrializados centrales no se ven golpeados frontalmente, aunque sus bolsas de valores resienten el flujo y reflujo de la especulación. Las megaempresas industriales, las grandes instituciones financieras, los monopolios de los medios de comunicación social, que no resienten en su interior los efectos de la crisis, no la perciben como una quiebra del modelo. Más aún, no se consideran responsables del debacle. Tal sentimiento parece ser compartido por el FMI, que no acepta "ser parte del problema”. Por ello, es más difícil hallar una solución a esta crisis. Ésta es la diferencia cualitativa con la crisis de 1930.

Lo que sí es cierto es que la crisis se venía gestando desde antes de los años 1990, tal como lo puso de manifiesto la cumbre mundial de Copenhague, en 1995: se desarrolla la pobreza, el cre-

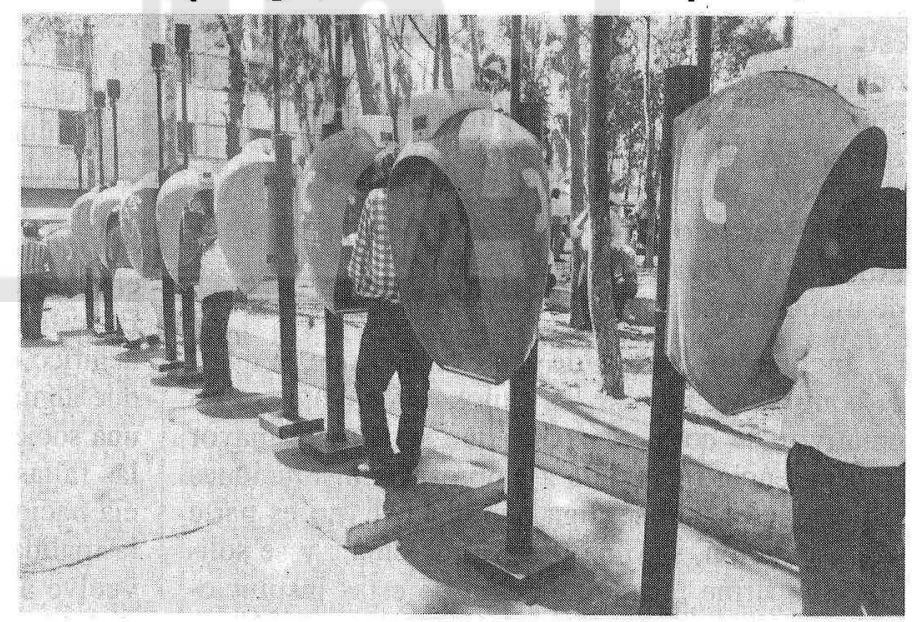


cimiento con desempleo y la insolidaridad social. También en las naciones del primer mundo aparecen los bolsones de pobreza-desempleo, la crisis de inseguridad de migrantes marginados y la creciente disparidad de ingresos, cuando el producto nacional que va a los asalariados ha disminuido alrededor del 10 por ciento $(E C A, 1998$, p. 898). Ahora se habla de un tercer mundo en el interior del primer mundo. En la convocatoria de Davos se ha vuelto a repetir que "La globalización debe adquirir un compromiso social, que no tenga como contrapartida la miseria y la exclusión de millones de seres humanos en el planeta". El Dr. J.D. Wolfensohn, en su discurso al Banco Mundial, el 6 de octubre de 1998, al referirse al bloque sudasiático constata la reaparición de la pobreza y de la crisis de inseguridad: "Hoy mis recuerdos son muy distintos. Imágenes sombrías, sobrecogedoras de desesperación, impotencia y miseria. De personas que tuvieron esperanza, pero la han perdido..." (ECA, 1998, p. 1004). Estas son las víctimas del comportamiento impulsivo neoliberal de sus grandes empresas y de sus sistemas financieros.

En Davos se ha dicho: "Los problemas creados por la mundialización han desembocado en una crisis "sistémica». O se diseñan nuevas medidas para hacer frente a la crisis o estamos condenados a entrar en un período de caos endémico y sistemático" (C. Swadja). Este tipo de reflexiones, emanadas desde países centrales, son las que pudieran crear conciencia en quienes aún no la tienen de que estamos en crisis. La presencia de un tercer mundo en el interior del primer mundo puede generar una luz de esperanza. También es cierto que la cumbre de Copenhague concluyó con una frustrada esperanza. Pero los países que viven este "caos endémico" necesitan ver luces de esperanza. El hecho de que en Europa la mayoría de gobiemos sean de centro-izquierda y que algo harán en ese sentido, es un signo de esperanza. El hecho de que se vuelva a hablar de Economía Social de Mercado (donde lo "social" no es un adorno) o se dialoga para modemizar el Estado social de bienestar, son también signos de esperanza.

Incluso son signos de esperanza el que se quiera controlar y regular los flujos de capitales especulativos de corto plazo; el que se solicite mayor transparencia financiera a empresas e instituciones bancarias; el que se diga que el FMI "no es parte de la solución, sino parte del problema", y se solicite una firme reestructuración de estas institucio- nes internacionales..., son otros signos de esperanza. Así como lo es también el hecho de que Juan Pablo II, que no es comunista, haya desacreditado y condenado al "neoliberalismo" en sus dos documentos de enero de 1999. Tal vez esto ayude a hacer el milagro de devolver la vista a los ciegos. Hay signos de esperanza que se encienden en sucesivos foros nacionales e internacionales.

\subsection{El Plan de Nación: ¿una tercera vía?}

En El Salvador hemos vivido la experiencia de "un primer mundo al interior del tercer mundo", y esto ha tenido consecuencias negativas para instaurar una economía de "rostro humano"; se aplican teorías y políticas de primer mundo para solventar problemas de tercer mundo. Desde una óptica y aspiración de primer mundo es difícil captar el "caos endémico" del tercer mundo. Hace diez años se implantó el credo neoliberal con gran triunfalismo y durante dos lustros hemos escuchado el estribillo de que estamos bien: economía sólida, sostenible, bien calificada por instituciones evaluadoras extranjeras, y preparada — con un tiempo de espera- para su dolarización. Ha habido un déficit de sinceridad con la verdad económica, social y también con la verdad ética. No es éste el ver y sentir de las mayorías, e incluso de grupos académicos profesiones, y ello ha generado una pérdida de credibilidad, así como una necesidad de participación y de búsqueda. Esto es un signo de esperanza que nace desde las infraestructuras.

Esta tensión apareció en el primer documento Bases para un plan de nación, en 1997, que motivó el diálogo y la participación, y que ha sido analizado más detalladamente en la obra "Temas claves para el Plan de Nación: consulta especializada", en enero de 1999. Es algo así como nuestro foro de Davos. Consulta especializada significa que así opinan más de 200 profesionales sobre temas claves de la nación, y ello desde ideologías divergentes. Es un avance el que se puedan emitir reflexiones no conformes con los grupos de poder y el que se puedan confrontar opiniones diferentes. En este documento no se vuelve a hacer un panegírico de los cuatro postulados económicos (aunque algunos están subyacentes), que nos llevarían a una sociedad libre y al desarrollo social. Al destacar las fallas estructurales en 19 áreas de la convivencia nacional se regenera una mayor sinceridad con la realidad y la verdad. Algo importante es que se vuelve al análisis estructural, sectorial y al mismo 
tiempo integrador de los órdenes político, económico, social, comprendidos los valores éticos y la administración de la justicia.

Con ello se declaran impertinentes y poco certeros los parámetros concentrados en cuatro variables macroeconómicas y se ponen en entredicho las publicitadas felicitaciones de evaluadores externos. No deja de ser algo irónico que quienes no prestan mayor crédito a las encuestas nacionales de opinión pública, sean tan crédulos de los evaluadores extemos. Éste es un espejismo del que nos pueden despertar, entre otros documentos, estos análisis de los temas claves para un Plan de Nación.

En esta misma dirección caminan los análisis de coyuntura económica de nuestro Departamento de Economía. "La secuencia de nuestros análisis coyunturales nos ha llevado a descubrir problemas estructurales de la economía salvadoreña. El crecimiento económico se debilita por el escaso poder de compra de los salarios, el raquítico crecimiento del consumo privado, las elevadas tasas de interés, el deterioro de la competitividad real y la delincuencia. En el sector público destaca el problema crónico de la evasión fiscal como uno de los factores que más inciden en la baja carga tributaria y el creciente déficit fiscal. En general, sin las remesas familiares las actuales condiciones económicas no serían sostenibles" (12 de febrero de 1999).

Esto significa que se están trazando los lineamientos para una tercera vía, integrando nuevos elementos en los reguladores Estado-Mercado. No es fácil hacer un ordenamiento prioritario de estos temas porque se trata de problemas interrelacionados e interdependientes. Lo siguiente es sólo un borrador. Se señala un efecto global: "Exclusión social y pobreza", que pasaría a ser el objetivo primario de las nuevas políticas. La exclusión social se explicita en el "Desarrollo agropecuario y rural". Se destacan estructuras frenos del crecimiento y del desarrollo: "Medio ambiente y desarrollo", "Ciencia y tecnología", "Nueva cultura laboral y empresarial", "Reformas de los sistemas de salud, vivienda, educación y cultura". Dos mesas analizan la integración económica interna y externa, dada su importancia en un horizonte globalizador: "Ramas estratégicas de desarrollo y reformas sectoriales pendientes", unido al tema mayor de la "Integración centroamericana, San José".

Muy en consonancia con nuestro análisis de coyuntura, el reto de la "Reforma fiscal y priorización de la inversión pública". Un eje transversal de todos los temas es la mesa 10: "Ética en El Salvador: crisis de valores y creencias", con su prolongación a la "Profundización de la reforma del sistema judicial". No pueden quedar en el tintero el recuerdo de los salvadoreños en el exterior, la formación cultural y profesional para la democracia y el desarrollo, así como aportes valiosos de la Mesa multidisciplinaria de Washington. Contamos con un amplio abanico de análisis, en espera del prometido resumen concentrado, que —en cierto sentido- hará más asequible su lectura.

De la integración armómica de todos estos temas llegaríamos a esclarecernos o debatir el punto de agenda siempre en litigio sobre "La modernización del Estado", que no es cuestión de un más o menos cuantitativo, sino de un Estado diferente. Sí existe un acuerdo general en relación con la "Descentralización y reorganización territorial". Por lo que respecta a la modernización del Estado, parecería traducirse una opinión extendida a favor de una Economía Social de Mercado, o una "Economía de Mercado con Equidad" (p. 89). Sin embargo, la mesa que analiza el tema (su redactor) deja constancia de que: "En la discusión sobre el rol del Estado, se expresan posiciones de carácter ideológico o doctrinario en torno a lo que debería ser el papel del Estado y el papel del Mercado en un momento histórico específico. La relación Estado-Mercado es el tema de fondo, que a veces se quiere soslayar". En la página siguiente se traslada una atinada afirmación del Ing. Héctor Dada Hirezi, quien concretiza esta problemática: “Apro- 
vechar la ventaja del mercado, limitando sus características concentradoras, aprovechar las ventajas de la intervención del Estado, sin caer en restricciones intolerables a la libertad social, es un objetivo difícil de lograr pero cuya búsqueda es una obligación...".

Este y otros trabajos constituyen un positivo aporte, en el momento oportuno, ya que coincide con el desencanto generalizado que han gestado el conjunto de partidos políticos. No sabemos, al redactar estas páginas, si habrá o no habrá un sensible absentismo electoral, pero sí se percibe un sensible desencanto político. Son los partidos políticos quienes debieran traducir estos análisis en programas de gobierno. Sería triste que tengamos que repetir la frase de Ota Sik: "Ni con unos ni con otros me puedo identificar en teoría". Lo menos que se puede pedir, en esta etapa de escucha y diálogo, es que el próximo gobierno no relege al olvido todo este conjunto de análisis. Un problema mayor es que un gobierno hereda de otro gobierno, junto con la banda presidencial, algunas malévolas inscrustaciones difíciles de arrancar. Un reciente editorial de Proceso las destaca puntualmente.

"En este momento, a la práctica política se asocian características no precisamente honrosas. Entre las más preocupantes están las siguientes: (a) corrupción y deshonestidad; (b) incompetencia profesional, que muchas veces raya en la ignorancia más palmaria; (c) predominio de los intereses particulares sobre la búqueda del bien común; $(d)$ elitismo antidemocrático, y $(e)$ existencia de una clase política resistente a la renovación interna. Estos aspectos han contribuido al desprestigio de la política, pues los valores éticos más profundos de ella — búsqueda del bien común, honestidad pública y privada, apertura a las mejores soluciones para garantizar el imperio de la justicia - han sido dejados de lado. En El Salvador, la política ha roto los vínculos con los criterios ético-normativos que son, precisamente, los que desde siempre han hecho de aquella una actividad socialmente necesaria y prestigiosa"14.

La Mesa multidisciplinaria de Washington repite similares observaciones (p. 357) y por ello agrega: "Es por lo anterior que, en la etapa en que se encuentra la democracia salvadoreña, se requieren mecanismos que incluyan en la reflexión sobre el país a sectores amplios, especialmente los que no tienen filiación política. Son también necesarios esquemas firmes que garanticen al ciudadano el ejercicio de pedirle cuentas a sus gobernantes y dirigentes y no solamente de elegirlos. Y, finalmente, se precisa un consenso básico y amplio sobre el destino del país, sancionado por el conjunto de la ciudadanía, que sirva de marco al juego de las fuerzas políticas y sociales" (p. 358).

Lo que estamos viendo y viviendo en El Salvador es un reflejo de las reflexiones y debates manifestados en Davos. Esto nos puede iluminar y nos debe animar. También entre nosotros existe un primer mundo dentro del tercer mundo, y se seguirá expresando porque tiene mucho poder. Poder para resistirse a los cambios e incluso poder para afirmar que no hay "caos endémico". Si en los países adinerados del hemisferio norte voces autorizadas condenan la desigualdad y se condena en los foros internacionales ante la presencia de los ejes poderosos del modelo, es lógico que colaboremos para romper "el largo silencio del neoliberalismo". Por añadidura, contamos con elementos suficientes para modelar una tercera vía con mayor sentido social y "de rostro humano".

14. Editorial de Proceso, 843, febrero, 1999. 